\title{
REDAÇÃO NA ESCOLA: O QUE OS PROFESSORES DIZEM E SILENCIAM SOBRE ESSA PRÁTICA
}

\author{
COMPOSITION WRITING AT SCHOOL: WHAT TEACHERS SAY AND SILENCE \\ ABOUT
}

Filomena Elaine P. ASSOLINI ${ }^{1}$

RESUMO: A preocupação com a escrita na escola, em especial com a prática de redação produzida por estudantes do ensino fundamental, instigou-nos à realização de ampla pesquisa, onde se investigou como os professores desse nível de ensino imaginam e discursivizam os alunos, nesse processo. O corpus foi constituído por depoimentos escritos de cerca de trinta professores do ensino fundamental, que ministram aulas em escolas públicas brasileiras. A partir desse vasto campo discursivo, realizamos alguns recortes. Sequências discursivas de referência foram por nós selecionadas, a partir dos recortes. Fundamentados na Análise de Discurso de Matriz Francesa, na Teoria Sócio-Histórica do Letramento, na Psicanálise freudolacaniana e nas Ciências da Educação, realizamos análises discursivas, cujos resultados indicam que: a) os professores concentram-se mais no que imaginam serem faltas e lacunas de saberes dos estudantes e menos em seus saberes escolares ou não acumulados; b) os professores não se entendem como profissionais capazes de lidar com o que pressupõem serem dificuldades dos alunos em relação à produção escrita; c) o discurso da oralidade de alguns alunos não é reconhecido nem valorizado pelos professores; d) eles imaginam que alguns alunos se encontram em nível zero de alfabetização e letramento, quando chegam à escola básica. A inscrição em formações discursivas que possibilitassem aos professores imaginarem os alunos como sujeitos que chegam à escola com algum nível de alfabetização e letramento poderia ajudá-los a desenvolver práticas pedagógicas escolares que considerassem a memória discursiva, memória de sentidos dos alunos, o que os levaria a se identificarem com sentidos aos quais se filiam. Entendemos ser urgente que o discurso narrativo seja incorporado aos conteúdos e práticas pedagógicas do ensino fundamental, pois, dentre outras possibilidades, esse discurso possibilita ao aluno manifestar sua subjetividade, condição fundamental para que possa produzir sentidos, ocupar o lugar de intérprete-historicizado e colocar-se como autor de seu próprio dizer. Entendemos que os cursos de formação inicial têm importante papel, no que se refere à oferta de experiências de escrita para os que estão em processo de aprendizagem da docência. Defendemos que o domínio dos saberes relacionados à escrita diferencia os alunos, assegurando-lhes participações mais amplas em práticas sociais.

PALAVRAS-CHAVE: Redação. Escrita. Alunos. Professores.

ABSTRACT: The concern with writing at elementary school instigated us to carry out a large study to investigate elementary school teachers' discourse about their students related to composition writing, that is, how teachers imagine their students' writing processes. Our corpus is selected from an ample field of discourse. Discursive sequences of reference were

${ }^{1}$ Universidade de São Paulo (Usp), Faculdade de Filosofia Ciências e Letras, Ribeirão Preto - SP - Brasil. Professora do Departamento de Educação, Informação e Comunicação. E-mail: elainefdoc @ ffclrp.usp.br. 
selected from cut-outs from written statements by approximately thirty elementary school teachers from Brazilian public schools. This investigation adopts the perspective of French Discourse Analysis, the Socio-Historical Theory of Literacy, Freud and Lacan's Psychoanalysis and in the Science of Education. Our results show that: a) teachers focus more on what they imagine to be students' flaws and gaps of knowledge, and less on students' cumulated knowledge; b) teachers do not see themselves as professionals capable of dealing with what they presume to be students' difficulties related to writing; c) some students' oral discourse is not acknowledged nor valued by teachers; d) teachers imagine some students to be at level zero of literacy as they start their schooling. We believe there can be a teachers' subscription into a discursive formation which allowed them to imagine their students as subjects who start school with some literacy background. With that in mind, teachers might develop a teaching practice considering discursive memory, students' memories and their meanings, leading them to identify with their original meanings. We see it as urgent that narrative discourse is incorporated to teaching practices and contents in elementary schools. Among other possibilities, the narrative discourse allows students to express their subjectivity. That is a fundamental condition to make sense of their own discourse, from the perspective of historicized-interpreter, and to become authors of their own speech. We believe that pre-service courses for teachers have an important role in offering writing experience for those learning to teach. We advocate the mastering of knowledge related to writing encourages differentiation among students, assuring them greater participation in social practices.

KEYWORDS: Composition. Writing. Students. Teachers.

\section{Introdução: situando a pesquisa e seus referenciais}

A preocupação com a escrita no contexto escolar, especialmente as redações produzidas por alunos do ensino fundamental, motivou-nos à realização de pesquisa onde se buscou compreender o que pensam os sujeitos-professores a respeito dos alunos, nesse processo. Mais especificamente, buscamos compreender como os alunos são imaginados e discursivizados pelos sujeitos-professores. Partimos do pressuposto segundo o qual, dependendo de como os alunos são imaginadas e discursivizados, as condições de produção do ensino da redação escrita, em sala de aula, dar-se-á de uma forma ou de outra. Ou seja, o ensino poderá possibilitar aos alunos ocuparem o lugar de intérpretes-historicizados, constituídos pela ideologia, inconsciente e subjetividade, ou se pautarem na pedagogia da repetição, que desconsidera os saberes acumulados pelo aluno, sua memória discursiva, nível de letramento, dentre outros conhecimentos.

Para alcançar nossos objetivos, valemo-nos de um aparato teórico, constituído pela Análise de Discurso de Matriz Francesa, pela Teoria Sócio-Histórica do Letramento, por 
alguns fios da Psicanálise freudo-lacaniana e, também, pelas contribuições advindas de estudiosos que se dedicam a pesquisas sobre formação inicial e continuada de professores.

Sendo assim, este artigo, dividi-se nas seguintes seções: a primeira traz a fundamentação teórica que sustenta a presente investigação, a segunda os aspectos metodológicos que nortearam nossa coleta de dados. Em seguida as análises discursivas, nascidas a partir de nossos gestos interpretativos e, por fim, algumas das conclusões às quais chegamos.

Feita essa breve introdução, daremos início à apresentação dos pontos teóricos basilares da Análise de Discurso Francesa.

\section{Fundamentos teóricos centrais da Análise de Discurso Pecheuxtiana}

Quando falamos em Análise do Discurso de matriz francesa (de ora em diante AD), referimo-nos à escola francesa de análise do discurso e ao grupo que se reuniu em torno de Michel Pêcheux, a partir dos anos sessenta.

Constituindo-se como uma teoria crítica da linguagem, a Análise do Discurso propõese a tratar da determinação histórica dos processos de produção de sentidos, procurando compreender o modo como um objeto simbólico produz sentidos, não a partir de um gesto automático de decodificação, mas a partir de procedimentos que desvendam a historicidade contida na linguagem, em seus mecanismos imaginários. Dessa forma, o fragmentário, o disperso, o incompleto e a opacidade também são de domínio da reflexão discursiva.

Em consequência disso, estudar a linguagem, a partir da perspectiva discursiva, significa abarcá-la nessa complexidade, significa, ainda, buscar entender e compreender o seu funcionamento.

O princípio teórico fundamental para a $\mathrm{AD}$ é a consideração de que há uma relação entre linguagem e exterioridade, que é constitutiva. Essa é uma relação orgânica, e não meramente adjetiva, supérflua. Dessa forma, os interlocutores, a situação, o contexto histórico-social, ideológico, isto é, as condições de produção não são meros complementos, pois eles constituem, segundo Pêcheux (1995), o sentido da sequência verbal produzida.

O objeto de estudo da $\mathrm{AD}$ é o discurso, sendo esse um objeto teórico, e não empírico. Definido não como transmissor de informações, mas como "[...] efeito de sentidos entre interlocutores." (PÊCHEUX; FUCHS, 1990, p. 170). Esses efeitos de sentidos constituem-se no processo de interlocução e, assim, se concretizam dentro de uma relação de forças estabelecidas pelos interlocutores, que são determinados sócio-historicamente. 
Reflitamos, agora, sobre dois conceitos clássicos em AD: formação ideológica e formação discursiva. Essa determina o que pode e deve ser dito, aquela o que pensar.

Outros conceitos fundamentais para a AD são os de sentido e sujeito. Tais conceitos não podem ser pensados separadamente, pois, de acordo com a perspectiva discursiva, o sentido não é algo que se dá, independentemente do sujeito. Ao significar, nós nos significamos. Assim, sujeito e sentido se configuram ao mesmo tempo, e é nisso que consistem os processos de identificação (ORLANDI, 1999).

Os mecanismos de produção de sentidos são os mesmos de produção dos sujeitos. Decorre daí o fato de buscarmos refletir simultaneamente sobre essas duas noções da AD.

A perspectiva discursiva vê nos protagonistas do discurso não a presença física de "organismos humanos individuais", “[...] mas a representação de lugares determinados na estrutura de uma formação social, lugares cujo feixe de traços objetivos característicos pode ser descrito pela sociologia." (ORLANDI, 1999, p.178).

Dessa forma, no interior de uma instituição escolar há o "lugar" do diretor, do professor, do aluno, cada um desses marcado por propriedades diferenciais.

\section{A abordagem sócio-histórica do letramento}

Comecemos pela definição de letramento, proposta pela linguista Tfouni (1995, p. 31, “[...] o letramento é um processo cuja natureza é sócio-histórica.” Dois aspectos merecem ser comentados: o primeiro diz respeito ao entendimento de que o letramento é processual, ou seja, podemos dizer que o sujeito inicia o letramento desde quando nasce, desde quando é inserido no universo do simbólico. O segundo tem a ver com a sua natureza sócio-histórica, o que nos permite dizer que tanto o sujeito do letramento quanto a língua, bem como a escrita e a leitura, são considerados dentro de contexto (sócio-histórico) que os determina e repercute na produção de sentidos.

A abordagem discursiva de letramento, enquanto processo, no qual se encaixa a alfabetização, abrange os aspectos sócio-históricos e ideológicos, referentes à aquisição da escrita por uma sociedade ou grupo de indivíduos; concentram-se, assim, no social e não no meramente individual, mesmo porquê, de acordo com essa abordagem, pensamos em sujeito, que ocupa posições discursivas, de acordo com as condições de produção nas quais produz o seu discurso.

As pesquisas nascidas da abordagem discursiva (sócio-histórica) de letramento, investigam não somente quem é alfabetizado, mas, também, aqueles que ainda não 
aprenderam o código escrito vigente, em determinada época. Tais pesquisas não se restringem ao âmbito particular, como é o caso dos estudos sobre alfabetização de maneira geral, e, por isso mesmo, diferenciam-se sobremaneira daquelas que se centralizam nos aspectos individuais da alfabetização.

Dentro desse contexto, vale destacar os contra-argumentos apresentados pela pesquisadora à afirmativa segundo a qual não-alfabetizados são incapazes de raciocinar logicamente, pensar em novos modos de categorização e solucionar problemas. De acordo com suas pesquisas, os não-alfabetizados têm, sim, capacidade para descentrar seu raciocínio, resolver conflitos e contradições que se estabelecem no plano da dialogia e ocupar o lugar de autor de seu próprio dizer. A explicação para isso, segundo Tfouni (1994, p. 27 grifo do autor),

[...] não está em ser ou não alfabetizado, enquanto indivíduo. Está, sim, em ser ou não letrada a sociedade na qual esses indivíduos vivem. Mais que isso: está na sofisticação das comunicações, dos modos de produção, das demandas cognitivas pelas quais passa uma sociedade como um todo quando se torna letrada, e que irão inevitavelmente influenciar aqueles que nela vivem, alfabetizados ou não.

No caso da sociedade contemporânea, não poderíamos ignorar as transformações e impactos trazidos pelas tecnologias de informação e comunicação, que nos trazem novos desafios, exigindo que saibamos lidar com toda a sorte de dispositivos inventados, diária e ininterruptamente.

Conceber o letramento como fenômeno sócio-histórico mais amplo que a alfabetização e buscar entendê-lo requer, portanto, investigar e compreender as transformações que ocorrem em uma sociedade, quando suas atividades passam a ser permeadas por um sistema de escrita, cujo uso é irrestrito e generalizado. Essas transformações, decorrentes do amplo uso do sistema de escrita, afetam-nos e influenciam nossas práticas de escrita, de leitura, pensamentos, (des)construção de raciocínios e argumentos. Ou seja, mesmo que não saibamos, o uso generalizado da escrita irá reverberar em nossos discursos e práticas culturais. Os sujeitos não-alfabetizados, que vivem em uma sociedade letrada, como é o caso da nossa, não estão isentos das influências da escrita e de suas práticas, independentemente de estarem inseridos no processo formal de escolarização.

Nessa linha de raciocínio, vale salientar que o termo iletrado não pode ser usado como antítese de "letrado", quando a sociedade é letrada, porque, segundo Tfouni (1995), não existe, nas sociedades industriais modernas, o letramento "grau zero". Todos nós, de 
diferentes formas, em diferentes graus, sofremos a influência da escrita. Sem dúvida, tal influência não se dá equanimemente, posto que não há possibilidade de igualdade, em uma sociedade globalizada e neoliberal.

A teoria sócio-histórica do letramento (abordagem discursiva) contrapõe-se ao pressuposto aceito resignadamente pelo discurso pedagógico escolar tradicional, DPE, de maneira particular, e pela instituição escolar, de forma ampla, de que o não leitor pode ser visto, imaginado e considerado iletrado, termo esse que, por sua vez, é tomado inquestionavelmente como sinônimo de analfabeto.

Para pensar os variados domínios da escrita, Tfouni desenvolveu a proposta de um continuum (TFOUNI, 1992, p. 26). Trata-se de uma linha imaginária, onde estariam as variadas posições discursivas disponíveis em uma sociedade letrada.

Dois aspectos relacionados a essa proposta devem ser ressaltados: o primeiro é que ela tem a ver com aspectos diacrônicos do social, pois, em um mesmo momento histórico, não se pode afirmar que as pessoas estejam no mesmo nível de desenvolvimento; o segundo é que os usos e funções sociais da escrita servem como parâmetros para o estabelecimento dessa proposta.

Do ponto de vista do letramento, a autora (TFOUNI, 1994, p. 56) concebe um eixo do tipo que a seguir apresentamos:

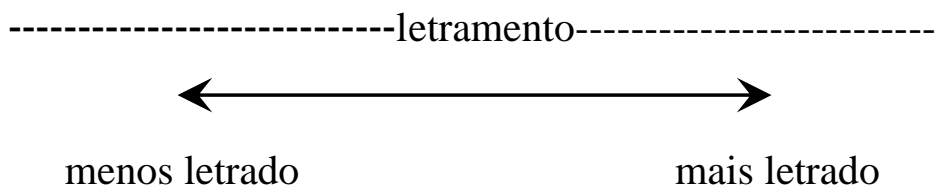

alfabetização

Vale destacar que, de acordo com a autora, nas várias gradações possíveis desse eixo, ficariam distribuídas as pessoas em um dado momento histórico. A linguista esclarece que, nesse eixo, “[...] não está implícito nem que essa distribuição seja homogênea, nem que essas posições sejam intercambiáveis ou equivalentes." (TFOUNI, 1994, p. 56). Assim, tanto do ponto de vista das desigualdades quanto do ponto de vista das aquisições levadas a efeito, temos diferenças.

Por todos esses motivos, entendemos que a proposta do continuum, de forma particular, bem como os postulados teóricos acerca do letramento e da alfabetização, de maneira geral, trazem relevantes contribuições para a educação escolar, para o professor alfabetizador e para os estudos sobre alfabetização, pois é possível observar, em uma mesma 
sala de aula, crianças em diferentes graus ou níveis de alfabetização e de letramento, se se considerarmos que o educando vive em uma sociedade permeada por um sistema de escrita, cujo uso é amplo e, portanto, sofre a influência (mesmo que indireta) do código escrito, não representaríamos o estudante como iletrado ou ignorante, apesar de não ser plenamente alfabetizado, posto que dispõe de algum conhecimento sobre a escrita, advindo de sua inserção em uma sociedade letrada.

\section{Aspectos metodológicos: constituição do campo e do corpus discursivo}

Na perspectiva teórica da $\mathrm{AD}$, consideramos a materialidade linguística no ponto em que se unem linguística, ideologia e inconsciente.

Tratar de aspectos metodológicos, no entanto, supõe teorizar novamente, pois, em AD, não há modelo único que poderia ser aplicado de modo indiferenciado a todo e qualquer discurso. A metodologia, assim, constrói-se num movimento contínuo, entre a teoria e a análise. Esse movimento contínuo foi denominado por Pêcheux (1995) de "batimento". São, pois, as indagações da pesquisa que determinam os procedimentos metodológicos necessários à analise do discurso que constitui o corpus discursivo.

É possível dizermos, então, com base em Courtine (1981), que, em AD, parte-se de um universal discursivo, entendido como um conjunto potencial de discursos que podem ser objeto de análise, para estabelecermos um campo discursivo de referência, constituído por um tipo de discursivo.

Partimos, assim, de um corpus empírico e chegamos a um corpus discursivo, que é o objeto sobre o qual incidem as análises.

Importa frisar que esse campo discursivo de referência representa um espaço (discursivo), a partir do qual o corpus discursivo é delimitado.

Selecionar o que pertence ou não ao corpus discursivo é tarefa do analista.

A próxima etapa é a seleção das sequências discursivas de referência, SDR, as quais podem ser orais ou escritas, de dimensão superior à frase (COURTINE, 1981).

Essas sequências discursivas são escolhidas de acordo com os objetivos da análise e organizadas em recortes discursivos, entendidos aqui como “[...] fragmento correlacionado de linguagem e situação." (ORLANDI, 1987, p.139).

Importa dizer que nos valeremos do paradigma indiciário, tal como proposto por Carlo Ginzburg (1989). As marcas e pistas linguístico-discursivas serão por nós identificadas e perscrutadas, visto que nos permitem puxar os fios do intradiscurso. Este remeter-nos-á às 
formações discursivas e às formações ideológicas que projetam. Esse processo possibilitarnos-á delinear as regularidades discursivas do dizer.

No processo metodológico, consideraremos a relação intradiscurso e interdiscurso. A observação desse nos permite remeter os dizeres dos professores a uma filiação de dizeres, a uma memória, e a identificá-la em sua historicidade, em sua significância, mostrando seus compromissos políticos e ideológicos. Aquele, o fio do discurso, o intradiscurso, permite-nos notar o que está sendo dito, naquele momento dado, em determinadas condições de produção.

Como bem elucida Courtine (1982), todo dizer se encontra na confluência de dois eixos: o da memória (constituição) e o da atualidade (formulação). E é a partir desse jogo que nascem os sentidos, sempre em movimento, sempre nos escapando, posto que o sujeito que se constitui no e pelo dizer está historicamente filiado a determinadas redes de sentido e não a outras, ou melhor, a determinadas formações discursivas e não a outras.

A AD, a Psicanálise freudo-lacaniana e a Ciência da Educação nos ensinam que a interpretação nunca é definitiva, única. Não há como dizer "interpretação concluída", ou, ainda, "conclusão final", posto que haverá sempre outros sentidos a serem desvendados e (re)produzidos.

\section{Condições de produção da coleta dos depoimentos escritos}

Os depoimentos escritos de trinta e dois sujeitos-professores efetivos de escolas públicas, estaduais e municipais, de uma importante cidade do interior paulista, foram coletados nas próprias escolas onde ministravam aulas, nos anos 2013 e 2014.

Eles foram por nós convidados a participar da pesquisa e a ela aderiram espontaneamente, tendo assinado o Termo de Consentimento Livre e Esclarecido. O convite foi feito por carta destinada às escolas, em um primeiro momento, e, posteriormente, também, por $e$-mail que lhes foi enviado.

Realizamos uma reunião coletiva, objetivando a apresentação do projeto, explicar como seria a dinâmica dos encontros, discorrer sobre a questão do sigilo e do Termo de Consentimento Livre e Esclarecido, falar sobre as atividades que lhes seriam propostas.

A partir de perguntas e problematizações desencadeadoras, por nós formuladas e a eles apresentadas, ao longo de seis diferentes encontros, redigiram seus depoimentos escritos, a respeito de diferentes temáticas, como alfabetização, letramento, redação, prática pedagógica escolar, livro didático, materiais curriculares oficiais de ensino, escrita, leitura, língua materna. 
Esse vasto "campo discursivo de referência" (COURTINE, 1981), deu origem a recortes, entendidos aqui como "[...] fragmentos correlacionados de linguagem e situação." (ORLANDI, 1987, p.139). Desses recortes, selecionamos algumas sequências discursivas de referência, SDR, às quais nos detivemos para construirmos nossas análises discursivas.

Os recortes e as sequências discursivas selecionados trazem os dizeres dos professores a respeito dos temas redação, escrita, alfabetização.

\section{Análises discursivas: compreendendo para lá das evidências de sentido}

\section{Recorte $\mathbf{n}^{\mathbf{0}} \mathbf{1}$}

\section{Recorte $\mathbf{n}^{\mathbf{0}} 2$}

É muito difícil trabalhar redação, as crianças acham ruim escrever, acham chato e a gente fica sem saber o que fazer com elas. A gente até apresenta propostas interessantes, mas mesmo assim elas não fazem; parece que os alunos têm medo de escrever (professor A).

O que eu tenho observado é que a cada ano que passa os alunos gostam menos de escrever, eles têm pavor só da gente falar que eles têm que fazer redação. Não sei, mas acho que os alunos ficam travados, congelados diante de uma folha de papel em branco, quando o assunto é redação. Não sei como agir (professor B).

Há um ponto comum nos recortes $n^{\circ} 1$ e $n^{\circ} 2$, ou seja, o fato de os alunos terem medo, pavor mesmo de escrever, ou, como afirma a posição-professor B, os alunos ficam travados, congelados, diante de uma folha de papel em branco.

Tendo em vista as afirmações acima destacadas, consideramos pertinente pensar sobre a questão da censura, pois, segundo Orlandi (1992), para que a censura funcione, ela joga com o princípio do autor: ela remete à responsabilidade do sujeito (autor) quanto ao que ele diz. A censura intervém e afeta a relação do indivíduo com sua identidade social e com o Estado. Definida como "[...] a interdição da inscrição do sujeito em formações discursivas determinadas.” (ORLANDI, 1992, p. 109), a censura, tal como pensada pela autora, relacionase à intervenção advinda de relações de força nas circunstâncias de enunciação: não se pode dizer aquilo que (se poderia dizer, mas) foi proibido.

Outro ponto a ser esclarecido é que a censura não é um fato da consciência individual do sujeito, mas um fato discursivo que se passa nos limites das diferentes formações discursivas que estão em relação com o dizível. De acordo com a autora do texto As formas do silêncio: 
[...] a censura sempre se dá na relação do dizer e do não poder dizer, do dizer de "um" e do dizer do "outro". É sempre em relação a um discurso outro que, na censura, terá a função do limite - que um sujeito será ou não autorizado a dizer. (ORLANDI, 1992, p. 112).

Feitas essas considerações, queremos destacar que o que temos observado no contexto escolar, na sala de aula, é que os alunos são efetivamente censurados (interditados). Sendo assim, o aluno submetido a ela (a censura) não pode dizer o que sabe ou o que gostaria de dizer: as crianças acham ruim escrever, acham chato, afirmam os professores. O silêncio da censura não significa ausência de informação, mas interdição da inscrição do sujeito em determinadas formações discursivas, especialmente aquelas que não podem circular no contexto escolar e na sala de aula. A afirmação da posição-professor B, eles têm pavor só da gente falar que eles têm que fazer redação, nos dá indícios de como a produção textual ocorre em condições de produção caracterizadas pela obrigatoriedade: têm que fazer redação.

O Discurso Pedagógico Escolar tradicional, DPE. ensina aos educandos que escrever consiste em uma tarefa que deve, necessariamente, ser realizada para se cumprir uma parte do currículo escolar ou para agradar o professor. Não nos causa indignação, portanto, que tal tarefa seja tomada pelos alunos como algo penoso, desgastante e sem sentido.

Podemos constatar, nos recortes acima apresentados, indícios linguístico-discursivos que nos mostram o quão inquietos os professores ficam diante da aversão dos alunos à produção de texto: a gente fica sem saber o que fazer com elas (as crianças), posiçãoprofessor A; não sei como agir, posição-professor B.

Entretanto, apesar de saberem de sua impotência frente ao desestímulo dos alunos, os professores não conseguem ocupar outra posição senão aquela em que permanecem submetidos às propostas e temáticas para a produção textual, trazidas pelos livros didáticos de português, de que se valem para o preparo de suas aulas. Salientamos que os professores entrevistados consideram viáveis apenas as temáticas e atividades de produção textual consideradas interessantes pelos autores de livros didáticos e não pelos alunos, ou por eles mesmos.

Dessa forma, o aluno não pode e não consegue, na maioria das vezes, inscrever-se num espaço interpretativo que lhe permitiria construir sentido, a partir das formações discursivas com as quais ele se identifica. Como tal sujeito é impingido a entrar em formações discursivas que se movimentam em outros lugares - os da autoridade do ensino -, ele se vê em uma situação contraditória: ao mesmo tempo em que lhe cobram que interprete e escreva 
sobre um determinado assunto, o sujeito é obrigado a inscrever-se em formações discursivas que não lhes são próprias, mas forçadas, às quais ele não se filia, portanto. Em decorrência disso, a identidade do sujeito é imediatamente afetada enquanto sujeito do discurso, pois, de acordo com Pêcheux (1995), a identidade resulta de processos de identificação segundo os quais o sujeito deve inscrever-se em uma (e não em outra) formação discursiva para que suas palavras tenham sentido.

Portanto, os alunos que têm como atividade escrever sobre "algo" permanecem presos e submetidos a um jogo que lhes abre alguns poucos espaços (o que a escola considera como legítimos) e outros não, uma vez que a censura não apenas impede a elaboração histórica dos sentidos, como também não lhes possibilita ocupar certos lugares, certas posições e identificarem-se com determinadas regiões do dizer, pelas quais se apresentam como sendo (socialmente) responsáveis, ou seja, como autores.

\section{Recorte n⿳ 3}

É impossível para esses alunos fazerem um texto, porque eles não escrevem
e não leem quase nada. Escrever uma produção textual não dá mesmo.
Falar até que vai tudo bem. Sei que eles gostam de contar histórias. Sei
também que hoje em dia falam pra gente valorizar isso. Eu conto muitas
histórias pras crianças, só que não posso ficar só nisso, tem o conteúdo, tem
o programa. As histórias que os alunos contam, os "causos" que eu conto
podem acontecer à vezes, mas tem coisa mais séria para passar pra eles
(professor C).

Nas sequências discursivas acima destacadas, podemos observar a separação feita pelo sujeito entre os usos orais e os usos escritos da língua.

Embora não saiba, a posição-professor $\mathrm{C}$ tem um discurso e uma prática sustentada pela teoria da grande divisa. Segundo Tfouni (1995), os autores que seguem essa teoria acreditam que a aquisição generalizada da escrita traz consequências de uma ordem tal que isso modifica, de maneira radical, as modalidades de comunicação de uma sociedade. Passariam a existir usos orais e usos escritos da língua e esses seriam separados, isolados, caracterizando, assim, a grande divisa.

A autora destaca, também, que é justamente o modelo autônomo de letramento que referenda cientificamente a tese da grande divisa. Esse modelo apela para a alfabetização como critério para estabelecer diferenças entre processos cognitivos, diferenças essas que se configurariam na forma de abismo intransponível entre aqueles que não sabem ler e escrever e aqueles que sabem. Ainda com base nos trabalhos de Tfouni (2001, 1995), destacamos que os autores que seguem a tese da grande divisa propõem uma separação dicotômica entre usos 
orais e usos escritos da língua, ao incorporarem a interpretação ideologicamente construída, segundo a qual a linguagem escrita seria superior à falada.

Entretanto, com base na abordagem discursiva de letramento, proposta por Tfouni (1995), podemos refutar e contrapormo-nos ao fato de que a questão da autoria limita-se à investigação de textos escritos, uma vez que o conceito de letramento, enquanto processo sócio-histórico, anula a teoria da grande divisa, antepondo ao modelo autônomo, que essa teoria postula, um modelo ideológico (STREET, 1989; TFOUNI, 1995; KLEIMAN, 1995).

Dessa forma, sendo histórico-social a natureza do letramento, de acordo com Tfouni (1995), tem-se que levar em consideração (tanto no sentido de analisar quanto no de valorizar) não somente as práticas escritas, mas, também, as práticas orais, pois, numa sociedade em que a escrita foi adotada predominantemente pela maioria da população, os mais variados meios culturais estão permeados pela sua utilização. Assim, por essa concepção, não podemos deixar de considerar inseridos no processo de letramento aqueles que não são alfabetizados. $\mathrm{O}$ conceito de base sócio-histórica para o letramento, proposto por Tfouni (1995), considera a existência, nas sociedades modernas, da interpenetração dos discursos orais e escritos.

Vale ressaltar, também, que, de acordo com os postulados de Tfouni (1995), não é mais a língua que é considerada como parâmetro, "[...] mas os discursos que servem de suporte às práticas letradas.” (TFOUNI, 2001, p. 82). A dicotomia língua oral/língua escrita já não serve mais e passa-se a considerar a interpenetração entre as modalidades oral e escrita.

Dentro disso, ressaltamos que a posição-professor C está inserida em formações discursivas que as fazem acreditar que somente o que está escrito e registrado é passível de reconhecimento e, como consequência, as histórias que os alunos contam sequer são consideradas, assim como seu arquivo e bagagem cultural, seu conhecimento de mundo, sua história de leitura, seu nível de letramento, enfim.

Nessa direção, entendemos ser de fundamental importância as contribuições de Tfouni (2001, 1996, 1995, 1994) que, dentre outros conceitos e postulados, mostram-nos que pode haver características de língua oral na escrita e vice-versa. Dessa forma, de acordo com a autora, o que é valorizado não é se o sujeito é alfabetizado ou não, mas, antes, em que medida esse sujeito pode ocupar a posição-autor. Vale enfatizar que essa posição também pode ser ocupada por aqueles que não aprenderam a ler e escrever. Portanto, mesmo que não dominem o código escrito de nossa sociedade, os alunos poderiam se estabelecer como autores de seu próprio dizer. Essa possibilidade, entretanto, não é valorizada pelos professores, em alguns casos. 
Outra sequência discursiva de referência que nos chama a atenção, referente à posiçãosujeito C é esta: os causos que eu conto podem acontecer às vezes, mas tem coisa mais séria praeles.

Podemos depreender que a professora considera que narrar histórias (causos) não constitui uma atividade pedagógica séria, que possa contribuir para o desenvolvimento infantil. A formação discursiva, na qual essa professora está inserida, faz com que ela acredite que o que pode e deve ser dito diz respeito apenas ao conteúdo pedagógico institucionalizado, não havendo, portanto, espaço e possibilidade para que outras formas de conhecimento (que não os legitimados) façam parte do processo educacional.

A nosso ver, entretanto, o trabalho de ensino-aprendizagem de leitura e escrita com narrativas poderia, dentre outras coisas, levar a criança a movimentar-se por outras formações discursivas que lhe permitissem, por exemplo, falar sobre suas próprias experiências, suas emoções, seus sentimentos, além de proporcionar-lhe oportunidades para criar e não apenas repetir o que a escola julga relevante.

A narrativa contrapõe-se à paráfrase, na medida em que aquela se caracteriza, sobretudo, por ser aberta à polissemia, e essa última pela reprodução de sentidos já existentes, o que impede o estabelecimento da função-autor.

Sendo assim, entendemos ser pertinente assinalar alguns aspectos referentes à narrativa que nos ajudarão a mostrar o porquê de considerarmos que a narrativa deve estar presente em sala de aula.

Destacamos que a função principal da narrativa é “[...] organizar através da linguagem, nossas interações, conhecimentos e experiências sobre o (no) mundo e com o Outro." (TFOUNI, 1995, p. 73). Para a pesquisadora, essa conceituação implica a consideração do discurso narrativo enquanto lugar por excelência, onde a subjetividade pode se instalar através de mecanismos linguístico-discursivos. Quanto ao que seja subjetividade, Tfouni (1995, p. 74) define-a de um ponto de vista discursivo, ou seja, "[...] a forma pela qual o sujeito organiza sua simbolização particular." Portanto, é através da narrativa que se torna possível (re)organizar e (re)elaborar nossas experiências pessoais.

A nosso ver, é necessária a incorporação do discurso narrativo (oral e escrito) nas práticas pedagógicas escolares, pois, além de ampliar o repertório linguístico-cultural dos alunos e proporcionar-lhes momentos de prazer, tal prática permite que os alunos se posicionem como intérpretes historicizados, tomando a escrita em seus aspectos linguísticos, histórico-sociais e cultural-ideológicos, bem como na memória dos alunos. Acrescentemos aqui o inconsciente, visto que certas marcas do sujeito desejante se inscrevem de forma única, 
ímpar, singular no processo e prática de (re)escrita. Sendo assim, “[...] a escrita só pode ser construída na medida em que mobiliza experiências que coloquem em movimento as estruturas do inconsciente do sujeito escrevente.” (RICKES, 2002, p. 46). A escrita pode, assim, ser considerada "marca, cicatriz".

\section{Recorte $n^{\circ} 4$}

Esses meninos estão praticamente analfabetos porque chegam pra gente em pleno quarto ano e não sabem ler e escrever, aliás eles não sabem nada, não conhecem nem as vogais. Eu não vou poder cumprir o programa da quarta, vou ter que alfabetizar, vou ter que começar do zero mesmo. (posiçãoprofessor D).

Os fragmentos destacados apontam que a posição-professor D está inserida em uma formação discursiva que a faz acreditar que os alunos, de maneira geral, não possuem saber algum sobre a leitura e a escrita: eles não_sabem nada, vou ter que começar do zero mesmo.

Entretanto, conforme mostra Tfouni (1995), as práticas sociais letradas influenciam todos os indivíduos de uma sociedade, de maneira desigual, é claro, pois os conhecimentos são distribuídos socialmente e, portanto, de forma desigual. A abordagem discursiva de letramento postula que viver em uma sociedade letrada é condição fundamental para que o indivíduo seja considerado letrado, seja ele alfabetizado ou não.

Dentro disso, consideramos que é fundamental que mostremos aos alunos a finalidade da escrita, bem como a utilidade social e prática da leitura e da escrita, pois, conforme afirma Tfouni (1996, p. 2), a escrita "[...] somente faz sentido dentro de práticas discursivas que permitam ao aprendiz olhar a escrita como um mediador entre ele, o mundo e o outro.’

Outra questão trazida pela autora e que, segundo nosso entendimento, consiste em uma relevante contribuição para os professores de maneira geral, diz respeito à proposta de alfabetizar a criança de maneira a torná-la letrada. Esse processo de alfabetização letrada pode ser levado a efeito "[...] tanto pela inserção de práticas de leitura e escrita em contextos cognitivos e comunicativos de experiência partilhada quanto pelo conhecimento da criança sobre os portadores de texto que estão servindo a essas práticas letradas, em um dado momento histórico.” (TFOUNI, 1994, p. 6).

Esse processo permite que a criança se torne um ativo participante na conversação histórica de sua cultura, podendo historicizar os sentidos. O texto escrito, por sua vez, assume suas efetivas características socioculturais e passa a ser visto como algo integrado a um portador de texto. 
Como podemos ver, para a pesquisadora e produtora da Teoria Sócio-Histórica do Letramento, e também para nós, o processo de tornar a criança letrada implica mostrar-lhe a utilidade prática e social da leitura e da escrita, bem como o fato de que ela (a criança) pode ocupar outros lugares para falar e escrever sobre si mesma. Se considerarmos que o educando vive em uma sociedade permeada por um sistema de escrita, cujo uso é amplo e generalizado e, portanto, sofre a influência, mesmo que indireta, do código escrito, certamente não o representaríamos como um aluno que chega à escola desprovido de qualquer conhecimento acerca da linguagem escrita, sem história(s) de letramento(s) algum(a), sem história(s) de leitura, enfim.

$\mathrm{Na}$ análise que estamos empreendendo, chama-nos a atenção também a sequência discursiva: (esses meninos) chegam pra gente em pleno quarto ano e não sabem ler $e$ escrever (posição-professor D).

A nosso ver, essa posição-professor está inserida em uma formação discursiva que a leva a entender que a aquisição de conhecimentos se dá em etapas fixas e definidas, ou seja, a cada ano letivo vivenciado na escola, o educando deveria necessariamente aprender os conteúdos determinados para aquela série. Assim, para essa posição-professor, caberia aos professores das séries antecedentes a tarefa de alfabetizar os alunos, sendo que a ela competiria cumprir o que considera o programa do quarto ano. A aprendizagem dos alunos deveria concretizar-se de forma linear, em degraus regulares e dentro dos muros escolares.

Nessa formação discursiva, o DPE coloca os professores em posições estanques e desarticuladas, como se cada uma das séries ou etapas para as quais ministram aulas fossem desvinculadas umas das outras. Dessa forma, os professores se entendem como sendo responsáveis apenas pela série, ou ano, que lhes foi destinada e não conseguem se ver como sujeitos integrantes de um sistema escolar, muito menos como sujeitos que podem e devem assumir lugares de profissionais da educação que têm o direito de criticar, contestar ou subverter um modelo pedagógico falho, que produz alunos não-alfabetizados ou com baixo nível de alfabetização.

Essas formações discursivas remetem a formações ideológicas segundo as quais a escola deve se submeter aos ditames de políticas neoliberais que, como sabemos, pressupõem que todos têm condições de alcançar o mesmo desempenho escolar e nível de letramento, independentemente de sua história de vida, condições de produção do ensino e da aprendizagem, memória discursiva, subjetividade. 


\section{Considerações finais}

Buscamos mostrar neste artigo como os professores do ensino fundamental imaginam e discursivizam os alunos, no processo de escrita, realizado sala de aula.

Um dos fatores por nós analisados diz respeito ao entendimento dos sujeitosprofessores de que as crianças não gostam de escrever e consideram a atividade de redigir textos desagradável.

Segundo o nosso entendimento, esse sujeito-aluno pode se entender censurado, no processo de produzir um texto, o que o impede de acionar a sua memória discursiva (memória de sentidos) e, também, a sua inscrição em formações discursivas com as quais se identifica.

Mobilizar a memória discursiva e, portanto, valer-se de sentidos que o afetam é condição fundamental para que possa redigir textos, orais ou escritos. Inscrever-se em formações discursivas com as quais se identifica é outro requisito importante para a produção escrita, pois, ao se identificar irá se filiar à rede de sentidos que tem a ver com o que pensa, sente, compreende, a respeito de diferentes temas, assuntos, fenômenos.

Observamos, também, que alguns professores desenvolvem sua prática pedagógica sob a égide da teoria da grande divisa, que faz separação radical entre os usos orais e usos escritos da língua. Como consequência disso, não conseguem valorizar situações importantes como, por exemplo, aquelas que os alunos contam espontaneamente histórias e causos.

A nosso ver, o reconhecimento e a valorização do discurso narrativo, oral e escrito, e o trabalho pedagógico com esse discurso na sala de aula é fundamental para que o aluno tenha oportunidade de (se)dizer, o que lhe permitiria expressar a sua subjetividade. Sem a consideração da subjetividade do aluno, é impossível uma prática pedagógica dialógica, bem como um trabalho que instigue os alunos a redigirem algo. Ter a oportunidade de falar de si é essencial para que os alunos aprendam a gostar de escrever e, por conseguinte, produzam os textos de diferentes gêneros.

Nessa linha de argumentação, gostaríamos de ressaltar que pensamos a escrita a partir de aspectos linguísticos, sócio-históricos, culturais e ideológicos, aos quais se soma o inconsciente, que sempre se inscreve na escrita do sujeito. Assim, a escola poderia desenvolver atividades de escrita a partir da mobilização de experiências vividas pelos alunos. Essas experiências poderiam colocar em movimento estruturas de seu inconsciente.

Detivemo-nos, também, em uma análise que nos diz sobre a possibilidade de o aluno estar em nível zero de escrita. Trata-se de um entendimento equivocado do sujeito-professor, pois, a partir da Teoria Sócio-Histórica do Letramento, sabemos que o letramento afeta todos 
os sujeitos de uma sociedade, em graus diferentes, certamente. Sendo assim, todos nós possuímos saberes sobre a escrita, independentemente de sermos alfabetizados ou não.

Considerar que o aluno chega à escola com algum nível de letramento e, a partir daí, iniciar o processo de alfabetização tem-se mostrado caminho exequível para tornar o sujeito alfabetizado e letrado.

Escrever não é tarefa fácil, nem para os alunos, nem para os professores. Sendo assim, consideramos que a escrita tem papel importante, nos cursos de formação inicial, pois, nesses cursos, existe a responsabilidade pela preparação profissional daqueles que irão exercer a docência, devendo cuidar de oferecer-lhes condições favoráveis de produção para que aprendam a expressar a sua subjetividade e vivenciarem experiências ricas de escrita. Sem essa experiência dificilmente conseguirão despertar o interesse dos alunos pela escrita ou incentivá-los à produção de um texto.

Em uma sociedade desigual como a nossa, saber escrever, ser alfabetizado e alcançar elevado nível de letramento diferencia os sujeitos. Além disso, se pensarmos que a história de nossa vida é um texto, podemos melhor escrevê-lo, ou, ainda, ressignificá-lo.

\section{REFERÊNCIAS}

COURTINE, J. J. Definition d'orientations théoriques et construction de procédures en anlyse du discours. Philosophiques, Montreal, v. 9, n. 2, p. 239-264, 1982.

COURTINE, J. J. Analyse du discours politique. Language, Paris, v. 62, p. 09-128, 1981.

GINZBURG, C. Sinais: raízes de um paradigma indiciário, In: GINZBURB, C. Mitos, emblemas, sinais: morfologia e história. São Paulo: Companhia de Letras, 1989. p. 143-179.

KLEIMAN, A. B. Os significados do letramento: uma nova perspectiva sobre a prática social da escrita. São Paulo: Mercado de Letras, 1995.

ORLANDI, E. P. Análise de discurso: princípios e procedimentos. Campinas: Pontes, 1999.

ORLANDI, E. P. As formas do silêncio no movimento dos sentidos. São Paulo: Ed. da UNICAMP, 1992.

ORLANDI, E. P. A linguagem e seu funcionamento São Paulo: Pontes, 1987.

PÊCHEUX, M. Semântica e discurso: uma crítica à afirmação do óbvio. São Paulo: Ed. da UNICAMP, 1995. 
PÊCHEUX, M.; FUCHS, C. A propósito da análise automática do discurso: atualização e perspectivas. In: GADET, F.; HAK, T. (Org.). Por uma análise automática do discurso. São Paulo: Ed. da UNICAMP, 1990. p. 163-252.

RICKES, S. M. A escritura como cicatriz. Educação e Realidade, Porto Alegre, n. 27, p. 5171, jan./jun. 2002.

STREET, B. Literacy in theory and practice: Cambridge: Cambridge University Press, 1989.

TFOUNI, L. V. A dispersão e a deriva na constituição da autoria e suas implicações para uma teoria de letramento. In: SIGNORINI, I. (Org.). Investigando a relação oral/escrito e as teorias do letramento. São Paulo: Mercado de Letras, 2001. p. 77-94.

TFOUNI, L. V. Letramento e alfabetização: colocações para uma reflexão sobre distúrbios de aprendizagem. Revista Psicopedagogia, [S.1.], v. 14, n. 32, p. 41-44, 1996.

TFOUNI, L.V. Letramento e alfabetização. São Paulo: Cortez, 1995.

TFOUNI, L.V. A escrita: remédio ou veneno? In: AZEVEDO, M. A.; MARQUES, M. L. (Org.). Alfabetização hoje. São Paulo: Cortez, 1994. p. 51-69.

TFOUNI, L.V. Letramento e analfabetismo. 1992. Tese (Livre-docência) - Faculdade de Filosofia, Ciências e Letras, Universidade de São Paulo, Ribeirão Preto, 1992.

\section{Como referenciar este artigo}

ASSOLINI, Filomena Elaine P. Redação na escola: o que os professores dizem e silenciam sobre essa prática. Doxa: Rev. Bras. Psicol. Educ., Araraquara, v.19, n.2, p. 240-257, jul./dez. 2017. e-ISSN: 2594-8385.

Submetido em: 10/05/2017

Aprovado em: 30/07/2017 